\title{
Surgical ethics: a framework for surgeons, patients, and society
}

\author{
Diana Cardenas, MD, PhD. ${ }^{1}[0$
}

\section{S u m m a r y}

\begin{abstract}
The practice of surgery is based on the technical capabilities of the surgeon (techne), their knowledge (episteme) and their capacity of judgment (phronesis). Surgeons face situations that call into question moral choices and face ethical difficulties in their daily practice. In fact, innovation is increasing, and as operations become more complex and the risks become greater, the tools necessary to approach an ethically challenging surgical case become more important. Surgical ethics can be distinguished from other medical ethics fields because of its unique characteristics and goals. Ethics lie at the core of professionalism: a proficient surgeon is considered to be not only competent to perform the art and science of surgery as traditionally understood, but also to be ethically and morally reliable. The principlism and the four-box model approaches to clinical ethics could serve as a guide to the surgical ethics discussion. There are five categories of experience and relationships that are especially important in surgery-rescue, proximity, ordeal, aftermath and presence. Ethical reasoning should help surgeons to gives answers to the questions: What should be done? Has the right decision in this situation been made?

The following article is presented with the intent of encouraging thought and dialogue about ethical considerations relevant to the practice of surgery. For that reason, we will first define the scope of surgical ethics, then we will present the main ethical issues faced by surgeons and how surgeons deal with them. Finally, I will show the implications of the development of surgery ethics for patients, surgeons and society.
\end{abstract}

Keywords: Ethics. Surgery. Principle-Based Ethics.

\section{Introduction}

$\square$ urgery can be defined as the action of man upon man. It can be conceived as both a passionate art, where the matter worked with is living flesh, and a science, where knowledge is dominated by the power of action. The French poet Paul Valery states in his Address to the College of Surgeons in 1938 "All of the science in the world cannot make an accomplished surgeon. It is the Doing that consecrates it". "In 1529, in "surgical" lessons at the Parisian Hospital I'Hôtel Dieu, the surgeon Ambroise Paré states: "Leafing through books and chatting or prattling about the operating room means nothing if the hands do not put into practice that which reason dictates ${ }^{2 "}$. Since then, it has been recognized that for surgeons, the main goal is not knowledge (episteme), but action (techne). During a surgery, there is always an action by one person, the surgeon, upon another person, the patient. The surgeons are thus required to complete surgical procedures differing greatly from other medical specialties where once a medical treatment is defined, it can continue without the direct involvement of the physician ${ }^{3}$.
Consequently, for surgery there's primacy of action over knowledge, and thus the definition of an ethics of action (i.e. surgical ethics) is necessary.

Ethics is a branch of philosophy that aims to conduct an intellectual analysis of the moral human dimension in all of its complexity. Ethics is concerned with the principles that allow us to make decisions about what is morally right and wrong ${ }^{4}$. Medical ethics deal with the principles that guide behavior and decisions that concern patients in the clinical field. A specific form of medical ethics - that some authors define as a branch of medical ethics - has emerged to deal with specific ethical issues and dilemmas specific to surgeons. In fact, surgery embodies several unique characteristics that justify the need for its own ethical approach. For example, surgery hurts before it heals, it is invasive and penetrates the patient's body and surgical decision-making is generally done under uncertain circumstances ${ }^{5}$. Moreover, the field of surgery evolves rapidly (i.e. innovation, robotics,) making the surgeon face new and ever more challenging ethical issues. The aim of this paper is to reflect upon surgical ethics and their role in the practice of surgery today.

1 - Faculty of Medicine Universidad El Bosque, Research Institute in Nutrition, Genetics and Metabolism - Bogota - Colômbia. 
Thus, I will first define the scope of this particular form of ethics, then present the main ethical issues faced by surgeons and how surgeons deal with them. Finally, I will show how ethics could impact the development of the discipline of surgery.

\section{Ethics in the Practice of Surgery}

The exponential availability of surgical technology and innovation ${ }^{6}$, its use of resources and the need to limit conflict of interest foster the development of surgical ethics today. However, the history of surgical ethics is as old as surgery itself. According to Namm et al., it dates back to ancient Mesopotamia and Egypt, but its peak can be placed during the eighteenth to the twenty-first centuries, when surgery emerged as the profession it is today ${ }^{7}$.

Surgical ethics are defined as the application of ethics to situations specific to surgical practice ${ }^{8}$. It is essential to supporting this discipline. Surgical ethics can be distinguished from other ethical fields because of their unique characteristics and goals ${ }^{7}$. Ethics of surgery are considered to be a special case of the general ethics of medicine. In fact, surgical ethics are not differentiated from general medical ethics by appeals to special kinds of principalism, virtue ethics, rights and duties, or by special context within microethics and macroethics ${ }^{9}$. In contrast, Mc Cullough, Jones and Brody defined the scope of surgical ethics as "the way in which the procedural nature of surgery and its capacity for bodily and psychic damage modify general ethical considerations such as virtues, consequences, rights, justice, and equality ${ }^{10 "}$.

The core of surgical ethics is the surgeonpatient relationship and the surgeon's responsibility to advance and protect the wellbeing of the patient. It emerged to examine problems specific to surgeons. These problems are closely linked to the development of science and technology. According to the French neurosurgeon Anne-Laure Boch, modern surgery is the place where science became technoscience, the place where knowledge became power ${ }^{11}$.
Scientific knowledge requires an infrastructure of technology in order to remain stationary or move forward. Thus, technoscience is where science and technology are linked and grow together. Recognizing that the aim of medicine (i.e. the art of heeling) is based on its efficacity, the development of science and technics in the surgical field during the XIX and XX centuries ensured that surgery achieved such a desired efficacity in the field of medicine. For that reason, the need arises for ethical principles to guide surgeons in their unique realms of medicine, surgery and the operating theater.

Surgical ethics can be described, according to Anne-Laure Boch, as being three axes which cover the major realities of surgery: 1) because surgery is a discipline oriented towards action rather than speculation, the surgeon needs an ethics of action; 2) because it related to the body considered as an object, there must be a well done work of ethics; 3) finally and most importantly, we need an ethics of relationship, this human relationship without which the technical prowess of surgery would be in vain ${ }^{11}$.

\section{Virtues in surgical ethics}

Decisions in surgery are based on appropriateness, acceptability and standards of care. In order to make decisions, surgeons need to be virtuous in modest qualities (e.g. perseverance, punctuality, fairness, honesty, kindness, teamwork, etc.) ${ }^{12}$, but also have a performance technique sufficient to perfectly master the complex art of surgery. This is acquired during extended education, and then as a repeated exercise in professional experience. Thus, this practical virtue is fed by discipline and perseverance. Most importantly, this virtue must be based upon the capacity of judgment or practical wisdom (i.e. phronesis). Phronesis is "a disposition accompanied by a just cause, turned to action and concerning that which is good or bad for man. ${ }^{13 "}$ 
Surgical technical performance cannot be the sole aim of surgery. It must be considered in perspective with the best interest of the patient and the proportionality of care. During surgical procedures, bodily penetration by incisions, cuts, sutures and cauterizations appears to disrespect the patient's integrity and to contradict the Hippocratic principle "primum non nocere". However, in order to heel the patient, this aggressive penetration into the patient's body by the surgeon is necessary, and for that reason, surgeons must separate the soul and the body, considering the body to be an "object". This object can be disrupted to be healed, and the spiritual part can be respected and sheltered to avoid damaging ${ }^{11}$.

Any disproportionate or futile surgery must be avoided and caregivers should not fall into therapeutic obstinacy. The latter is defined as acts that appear unnecessary, disproportionate or having no effect other than the mere artificial maintenance of life ${ }^{14}$. It is thus legally and ethically accepted to not operate on a patient if it is considered to be obstinacy or futile. Such a clinical decision must be made in the best interests of the patient, and must respect the wishes previously expressed by patients when possible. If there are no advance directives, the decision can legally be made in accordance with the presumed wishes of the patient, or using information passed on by relatives or legally appointed healthcare agents.

The questions futility raises are more important now than ever in the field of surgery. Improved technology and critical care techniques have given surgery and medicine the ability to prolong life in the most extreme circumstances. However, in view of the great increase of technological improvements, continuous pressure on the healthcare system to limit costs is contradictory. According to Grant et al., the ethical principles underlying medical futility are especially pronounced in the surgical care of patients ${ }^{15}$.
- Surgery is often sought or considered for severely ill patients for whom futility discussions are most relevant.

- Surgical intervention has great potential for harm to the patient and routinely requires balancing the ethical principles of beneficence and nonmaleficence.

- Surgery requires the consent of multiple agents: patient, surgeon, and anesthesiologist.

- Questions of patient autonomy and a physician's obligation to provide treatment are common in futility discussions and can be especially complex in cases in which surgical intervention is being considered.

Surgeons face the challenge of successfully resolving futility disputes mainly when there is significant disagreement between the health care team and the patient and/or surrogate decision makers. These disputes may be founded on the lack of a common definition of futility interventions in the field of surgery. Some authors distinguished between quantitative and qualitative futility ${ }^{14,16}$. Quantitative futility, often considered synonymous with physiologic futility, relies on the scientific assessment of the probability of success. For example, an intervention with a low probability of success, such as 1 in 1,000 is considered futile by some but not others ${ }^{15}$. Most authors do not give a numerical threshold for this probability, and the decision must be made in the context of each individual patient. To arrive at the conclusion of futility, the clinician must rely upon high-quality clinical evidence, when available, and upon his or her experience and judgment when applicable evidence is not available.

The most controversial thing is the definition of 'qualitative futility', which describes a situation in which the treatment provided is likely to result in an unacceptable quality of life or in an insufficient or unacceptable functional status. 
In fact, identifying universally acceptable quality outcomes is impossible given the variety of moral and cultural beliefs held by patients. However, authors set a limit to what should be considered to be a qualitatively futile result: "the continued biologic life without conscious autonomy ${ }^{15 " .}$

The key to favoring phronesis is to have direct and honest discussions with patients and families regarding the goals of care. This can help avoid futility conflicts and improve surgical outcomes.

\section{Ethical issues in surgery}

Surgical decision-making can be viewed as a two-part process. First, there is the 'is it possible to treat' or 'how to treat' aspect, which is a matter of knowledge and technique (i.e. surgical science). This is translated into an evidence-based practice. Secondly, the 'why treat' or 'what should be done' issues, which are a matter of surgical ethics and should be based on moral philosophy ${ }^{17}$. The kind of ethical dilemmas surgeons face have been previously studied. Torjuul et al. describe the kinds of ethical dilemmas 10 surgeons at a University hospital in Norway face when they practice $^{18}$. The main finding was that surgeons experienced ethical dilemmas in deciding on the right treatment in different situations: starting or withholding treatment, continuing or withdrawing treatment, overtreatment, respecting the patients and meeting patients' expectations. Ferreres et al. surveyed 130 surgeons and have identified the fact that the most frequent ethical issues were facing decisions in terminal patients, refusal of surgical intervention, risk of futility, uncertainty about the best treatment goal, and communication ${ }^{19}$.

Other authors suggest that innovation can also engage ethical issues in surgery ${ }^{20}$. In fact, innovation is responsible for most of the advances in the field of surgery. Innovative approaches to solving clinical problems have significantly decreased morbidity and mortality for many surgical procedures, and have led to improved patient outcomes ${ }^{21}$.
However, not all innovations are successful or result in improved patient care ${ }^{21}$. At the core of the ethical dilemmas in surgical innovation are the risks and benefits to patients, particularly with respect to safety and potential harm. Most of the time, due to the inherent nature of innovation, the real risks of a new technique may not be known at the time of implementation if a particular risk is very small and infrequent. An innovative approach might have to be studied in thousands of patients to assess whether it is as safe as the traditional approach. The uncertainty of the interest of a particular innovation creates challenges for surgeons, patients, and the healthcare system.

Not all surgeons may face this challenge in the same way. Reitsma et al. investigated the definitions, opinions, and attitudes of 655 surgeons in the United States about innovative surgery. Respondents expressed a fairly prudent stance when judging hypothetical innovative scenarios ${ }^{21}$. In a qualitative study, Zarzavadjian Le Bian et al., described that ethical conflicts were related to risk assessment and doubts regarding methodology, and most participants described ethical dilemma as being irrelevant ${ }^{22}$. Table 1 shows the ethical considerations relevant to the implementation of new surgical technologies and techniques. This consideration could serve to encourage thought and dialogue about ethical considerations relevant to the implementation of new technologies and new techniques in surgery.

Thus, surgeons must reason according to an ethics of action perspective. This means explaining the choices of actions in situations in which it is unclear as to what the right thing to do is. Ethical dilemmas occur when physicians have to choose between at least two alternative and equally difficult courses of actions $^{18}$. Sometimes, because neither of the alternatives have positive outcomes, surgeons have to choose between the least bad option. 
Table 1. Ethical considerations relevant to the implementation of new surgical technologies and techniques ${ }^{6}$.

- How is the safety of a new technology or technique ensured?
- What is the timing and process by which a new technology or technique is implemented at
- How are patients informed before undergoing a new technology or technique?
- How are surgeons trained and credentialed in a new technology or technique?
- How are the outcomes of a new technology or technique tracked and evaluated?
- How are the responsibilities to individual patients and society at large balanced?

Ethical dilemmas can also be understood as being those situations in which there is a conflict or tension between respecting two or more principles that make it difficult to decide what should be done. This means that when a surgeon has an ethical dilemma, it is because he or she does not know which particular principle or moral value should be upheld in that situation. Consequently, two question arise: 1) How does one think about an ethical case? And 2) is there a method or a guide that could help surgeons decide?

\section{Methodology in ethics: Principlism and the four- box model approach to clinical ethics}

When deciding on 'why to treat', ethics provides us with four principles: beneficence, nonmaleficence, respect for patient autonomy, and justice. These principles guide the evaluation and interpretation of ethical issues in patient care. These ethical principles proposed by Beauchamp and Childress are internationally recognized ${ }^{14}$. They are known as principlism or the 'four-principle' approach, and are conceived to be part of a common moral ground that enables a practical approach to ethical decision-making. This means that those four principles aspire to be applied universally and constitute the framework of a "common morality", that is to say, a collection of very general norms to which all those who deal with morality can subscribe.
The four principles are accepted as the basis for making moral decisions in medicine and surgery. It is important to note that this approach should be seen not as a checklist of actions that will inform doctors about the appropriate action for any circumstance, but rather as a "framework of virtues or values that are relevant to ethical debate ${ }^{23 "}$. Table 2 shows the definition of the four principles and their practical application in surgery.

How to think about an ethical case? Among different methods, in their book Clinical Ethics, Jonsen et al. describe a four-box model approach to clinical ethics ${ }^{24}$ (Figure 1). The four areas to be addressed include: medical indications, patient preferences, quality of life, and contextual features. To approach this model, a surgeon must first gather all the facts about a patient's care by examining multiple dimensions of the patient's life, health, and desires. This method prevents the surgeons from only focusing on the medical issues and encourages taking the time to reflect on other aspects of the patient's life and how this could effect decisions. For a detailed explanation of this model with focus on surgery, see Wightman and Angelos' paper $^{3}$.

From an ethical perspective, it is possible to wonder: what are the patients' expectations regarding the ethical and moral behavior of the surgeon? 
Table 2. The practical approach of principlism in surgery

\section{Principle: Respect for autonomy}

\section{Definition}

Patients should be treated as autonomous agents. This means recognizing the individual's capacity for self-determination, their ability to make independent decisions and authentic choices based on personal values and beliefs.

- Patients with diminished autonomy are entitled to protection.

- Autonomy does not mean that a patient has the right to obtain any treatment he or she wishes or requests if this particular treatment is not medically indicated.

- Autonomy can only be exercised after having obtained full and appropriate information as well as having understood it. The decision has to be taken without any undue coercion or pressure.

\section{Informed consent}

Informed consent plays a highly significant role in the patient-surgeon relationship. For patients waiting to undergo surgery, obtaining informed consent is the surgeon's final step in the information process, and giving informed consent is an important decision that the patient must make freely and independently ${ }^{25}$.

For informed consent in surgery, the legal principle emphasizes that the patient is an independent adult who has the capacity and the competence to authorize that which is going to be done to their body and mind. Therefore, any operation that may infringe upon this principle is not only considered to be illegal and liable to result in lawsuits for unlawful injury caused to the patient, it is also ethically unacceptable ${ }^{26}$.

\section{Principle: Beneficence}

\section{Definition}

The principle of beneficence imposes an obligation to act for the benefit of the patient.

Surgeons have to follow professional obligations and standards. Surgeons should provide appropriate surgical intervention in response to a medical indication and following the consent of the patient.

Each decision must be taken on an individual level.

\section{Principle: Non-maleficence}

\section{Definition}

The principle of nonmaleficence imposes an obligation not to inflict harm on others. Surgery should minimize possible harm.

Surgeons must assess the nature and scope of the risks and benefits.

\section{Statements}

The patient must be adequately informed about the benefits and risks of the proposed surgical treatment.

The patient has the right to decide whether or not to accept treatment.

A competent patient has the right to refuse a treatment after adequate information, even when this refusal would lead to his or her death.

\section{Statements}

Surgeons have the obligation to maximize potential benefits for their patients while at the same time minimizing potential harm for them

The patient must not be deceived.

\section{Statements}

If the risks and burdens of a given surgery for a specific patient outweigh the potential benefits, then the surgeon has an obligation not to operate. 
...continue

\section{Principle: Justice}

The principle of justice refers to equal access to health care for all. Limited resources including the time surgeons and other health personnel and caregivers devote to their patients must be evenly distributed to achieve a true benefit for the patient. Resources should be distributed fairly without any discrimination. With regard to limited resources, there must be proper use of ethically appropriate and transparent criteria.
Every patient is entitled to obtain the best surgical care available.

Expensive surgeries should always, like any other therapy, be provided solely when indicated.

Undertreatment should never be the result of containing the growing costs of healthcare.

Patients have the right to have their health valued more highly than the surgeon's own economic interest.

\begin{tabular}{|l|l|}
\hline Medical Indication & Patient Preferences \\
- Medical problem & - Informed of risks \\
- Goals of treatment & - Understands benefits \\
- Treatment options and alternatives & - Patient has decisional capacity? \\
- Likely success of treatment & - Preferences \\
\hline $\begin{array}{l}\text { Quality of Life } \\
\text { - Baseline functionality }\end{array}$ & - Surrogates \\
- Current lifestyle and independence & - Personal interests \\
- Expected time of recovery & - Financial incentives \\
- Possible deficits resulting from & - Professional biases \\
treatment & - Research conflicts \\
& - Hospital pressures \\
\hline
\end{tabular}

Figure 1. Four-box model approach to clinical ethics. Adapted from Jonsen AR, Sieger M, Winslade WJ. Clinical Ethics: A Practical Approach to Ethical Decisions in Clinical Medicine. 8th ed. New York, NY: McGraw-Hills; $2015^{24 .}$

5. Patients' expectations: Rescue, proximity, ordeal, aftermath and presence

Surgical ethics were defined by the English surgeon Miles Little in five categories within the moral domain of the surgical relationship: 1) Rescue, 2) Proximity, 3) Ordeal, 4) Aftermath and 5) Presence ${ }^{8}$.
The sense of rescue, the feeling of relational proximity, the ordeal and the aftermath of surgery are things that the patient experiences. Surgeons must recognize the patient's need to be rescued. At the same time, surgeons may need help and to be rescued by other surgeons in case of difficulties in diagnosis, management or operations. 
Thus, rescue is, according to Little, the main pillar of surgical ethics. The patients need a particular proximity with surgeons. This proximity will allow the surgeon to understand patients' suffering and specific needs 8,9 . According to Little, being aware of these experiences and integrating that presence is ethically normative, and could allow surgeons to understand that which may be asked of them in an ethical sense ${ }^{8}$.

A proficient surgeon is considered to be not only competent to perform the art and science of surgery as traditionally understood, but also to be ethically and morally reliable. According to Pellegrini, the tenets of a modern competent surgeon include the following characteristics: 1) good clinical skills and appropriate surgical judgment; 2) good technical skills, including knowledge of and expertise in the performance of operations; 3 ) knowledge and practice of humanism, ethics, and solid moral values ${ }^{17}$.

\section{Implications and perspectives for the development of surgical ethics}

Surgical ethics are an essential component in contemporary surgical practice. The success of even the most technically skillful surgery requires an ethical approach. In fact, what makes a good surgeon is the balance of technical questions and surgical ethics reasoning. The acknowledgement of the importance of surgery ethics should have implications to patients, surgeons, and society.

As for patients, they must recognize the power of the surgeons, a power socially endorsed. This power is derived from the technical capabilities of the surgeon (techne), their knowledge (episteme) and their capacity of judgment (phronesis). In any case, said power is considered to be domination or annihilation, but is instead a relationship founded by surrender that presupposes rescue ${ }^{9}$.

Society and institutions should be informed and be aware of the particularities and the challenges that surgeons face in daily practice.
They should contribute to creating a favorable atmosphere for a humanistic practice. Surgeons must stop being regarded as callous, tireless and invincible professionals. Concerning futility in surgery, community and/or institutional standards can be created proactively in order to create evaluation criteria for defining or recognizing futility and establishing a process for addressing futility claims on a case-by-case basis. Different ethical spaces such as institutional committees or discussion groups should be promoted.

Surgeons should be skilled in the art and science of surgery and be trustworthy from an ethical and moral standpoint. They must recognize that the nature of surgical work provides fertile ground in which ethical problems can grow ${ }^{1}$, and thus, they need to be aware of and prepared for this. Surgeons should rely upon their judgment and their values and beliefs to make ethical decisions, and if necessary, to take difficult decisions to an ethical consultation or committee. Thus, education at the resident level is important for several reasons. First, it can promote humanism and professionalism based on human values, and in consequence, care could be delivered in a socially and ethically responsible manner. Education on ethics can contribute to making surgeons more culturally competent. Secondly, It can make surgeons better prepared to make the ethical decisions they confront in daily practice, the application of new technologies and in a surgical environment that is becoming increasingly institutionalized and under economic pressures. Resident ethics education provides the opportunity for a model of collective deliberation to be developed that can be used to make sense of ethical problems as they arise. An ethical curriculum should be part of a broader curriculum in humanities ${ }^{25}$. This way, surgery will not be conceived merely as a practice of applied technology, but as the humanistic art of healing. 


\section{References}

1. Valery P. Discours aux chirurgiens. Congrès français de chirurgie. 1938. St Amand: Editions Gallimard; 2010. p. 587.

2. Ambroise Paré. In: La Grand Larousse Encyclopédie [Internet]. (Accessed 2020 Jan 15). Available from: https://www.larousse.fr/archives/grandeencyclopedie/page/3068.

3. Wightman SC, Angelos P. An organized approach to complex ethical cases on a surgical service. World J Surg. 2014;38(7):1664-7.

4. Paul Ricoeur P. In: Canto-Sperber $M$, éditeur. Éthique, Dictionnaire d'éthique et de philosophie morale. Paris: PUF; 2004. p. 689.

5. Ferreres AR. Ética y Cirugía en el siglo XXI. Cir Esp. 2015;93(6):357-8.

6. Miller ME, Siegler $M$, Angelos P. Ethical issues in surgical innovation. World J Surg. 2014;38(7):1638-43.

7. Namm JP, Siegler M, Brander C, Kim TY, Lowe Ch, Angelos P. History and Evolution of Surgical Ethics: John Gregory to the Twenty-first Century. World J Surg. 2014;38(7):1568-73.

8. Little $M$. The fivefold root of an ethics of surgery. Bioethics. 2002;16(3):183-201.

9. Little M. Invited commentary: Is there a distinctively surgical ethics [editorial]? Surgery. 2001;129(6):668-71.

10. McCullough LB, Jones JW, Brody BA, editors. Surgical ethics. Oxford University Press: New York; 1998.

11. Boch AL. Une éthique pour la chirurgie. In: Hirsch E, éditeur. Traité de bioéthique. II - Soigner la personne, évolutions, innovations thérapeutiques. Toulouse, France: ERES; 2010.p. 633-43.

12. Kotzee $B$, Ignatowicz $A$, Thomas $H$. Virtue in medical practice: an exploratory study. HECForum. 2017;29910:1-19.

13. Aristote. Éthique à Nicomaque. Trad. J Voilquin. Paris: Garnier-Flammarion; 1992. VI5.

14. Beauchamp TL, Childress JF. Principles of Biomedical Ethics. 8th ed. New York: Oxford University Press; 2019.
15. Grant SB, Modi PK, Singer EA. Futility and the care of surgical patients: ethical dilemmas. World J Surg. 2014;38(7):1631-7.

16. Schneiderman LJ, Jecker NS, Jonsen AR. Medical futility: its meaning and ethical implications. Ann Intern Med. 1990;112(12):949-54.

17. Pellegrini CA, Ferreres A. Surgical Ethics Symposium "Ethical dilemmas in surgical practice". World J Surg. 2014;38(7):1565-6.

18. Torjuul K, Nordam A, Sørlie V. Action ethical dilemmas in surgery: an interview study of practicing surgeons. BMC Med Ethics. 2005;6:E7.

19. Ferreres AR, Miguel PJ, Trapani RJ, Camelione JJ, Cardozo L, Curvale $P$, et al. How do surgeons face ethical conflicts? A qualitative analysis. J Am Coll Surg. 2016;223(4):S47-S48.

20. Strong VE, Forde KA, MacFadyen BV, Mellinger JD, Crookes PF, Sillin LF, et al. Ethical considerations regarding the implementation of new technologies and techniques in surgery. Surg Endosc. 2014;28(8):2272-6.

21. Reitsma AM, Moreno JD. Ethics of innovative surgery: US surgeons' definitions, knowledge, and attitudes. J Am Coll Surg. 2005;200(1):103-10.

22. Zarzavadjian Le Bian AZ, Fuks D, Costi R, Cesaretti $M$, Bruderer $A$, Wind $P$, et al. Innovation in Surgery: qualitative analysis of the decisionmaking process and ethical concerns. Surg Innov. 2018 Jul 1[Online ahead of print]. https://doi doi: $10.1177 / 1553350618789265$.

23. McNaught $C$, MacFie J. Ethics and Nutrition. In: Elia $M$, Ljungqvist $O$, Stratton RJ, Lanhan-New S, Davies DSC, editors. Clinical Nutrition. 2nd ed. Scarborough: Blackwell Publishing; 2013.

24. Jonsen $A R$, Siegler $M$, Winslade WJ. Clinical ethics: a practical approach to ethical decisions in clinical medicine. 7th ed. New York: McGraw Hill Professional; 2006.

25. Keune JD, Kodner IJ. The importance of an ethics curriculum in surgical education. World J Surg. 2014;38(7):1581-6.

26. Cainzos MA, González-Vinagre S. Informed Consent in Surgery. World J Surg. 2014;38(7):1587-93. 
Recebido em: 01/03/2020

Aceito para publicação em: 01/03/2020

"Medicine is an intensely moral activity" A tribute to Doctor José Félix Patiño Restrepo February 15 1927February 26 2020. I wish to dedicate this article to the Colombian Professor José Félix Patiño Restrepo who gave an elevated ethical sense to the practice of surgery" Medicine is an intensely moral profession" A tribute to Professor José Félix Patiño Restrepo 1927-2020.

\section{Mailing address:}

Diana Cardenas

E-mail: Dianacardenasbraz@gmail.com 